\title{
THE IMPACT OF NATURAL CATASTROPHES AND CLIMATE CHANGE ON INSURERS
}

\author{
Lecturer PhD Flavia Barna, \\ flavia.barna@fse.uvt.ro \\ West University of Timisoara, Romania
}

Abstract:

In last year, a record number of catastrophes caused untold damage and misery around the world. The indications are that national catastrophes will continue to increase in frequency and in terms of their economic impact. This paper discusses the recent changes in the market for catastrophe risk. These risks have traditionally been distributed through the insurance and reinsurance systems.

Insurance is in the front line of climate change, as it is often insurers and re-insurers that have the responsibility to deal with its consequences. Climate change presents a range of challenges and opportunities to the insurance industry, affecting many business lines (e.g. property \& casualty, agriculture and health insurance).

The number of worldwide catastrophic events as well as the insured losses has increased over the last 35 years. For the second year running, insured losses due to natural catastrophes hit a record high, totaling $\$ 83$ bn in 2005. About $8.4 \%$ of these losses were caused by natural events in Europe. In addition, a large part of the recorded losses in 2004 and 2005 which were caused by hurricanes in the North America, were also paid for by European insurers and reinsures.

Graph 1

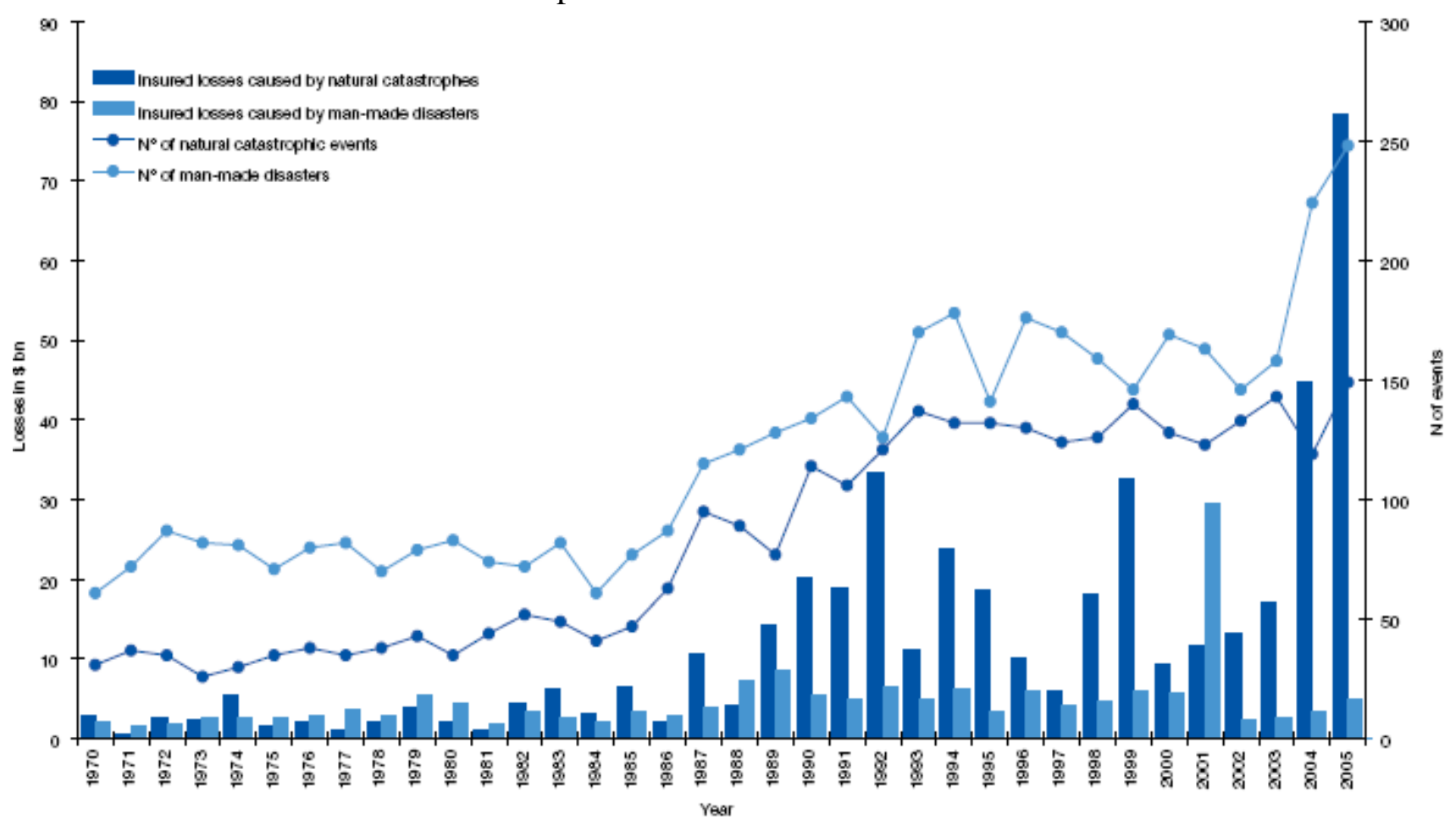

Source: ABI (2005), Financial risks of climate change 
Risk measurement and the calculation of insurance prices in relation to weather-related catastrophes has typically been retrospective (looking at the loss experience in the past). As climate change is altering the global risk environment, a more forward-looking approach is required. Hence insurers are making use of geo-scientific methods of analysis, such as geographical information systems, risk mapping and event scenarios.

Adequate risk assessment and measurement is not only essential for the insurance sector but also for the society and policy-makers. By quantifying the expected changes of future weather related events and incorporating them in the premium calculations, insurance prices provide clear signals about the size of climate risks. Moreover, these quantitative approaches ensure that policy-makers can consider the full social, economic and financial consequences of catastrophic scenarios for a specific region when they decide on land-use plans.

The insured losses caused by natural catastrophes and their volatility will rise. Therefore, with a stable insurance coverage, insurance companies will have to cope with an increasing average and maximum loss burden. Sufficient capital is required to bridge the gap between expected and extreme losses.

Impact of Climate Change on Portability Loss Distribution and Implications for Risk Capital Requirements

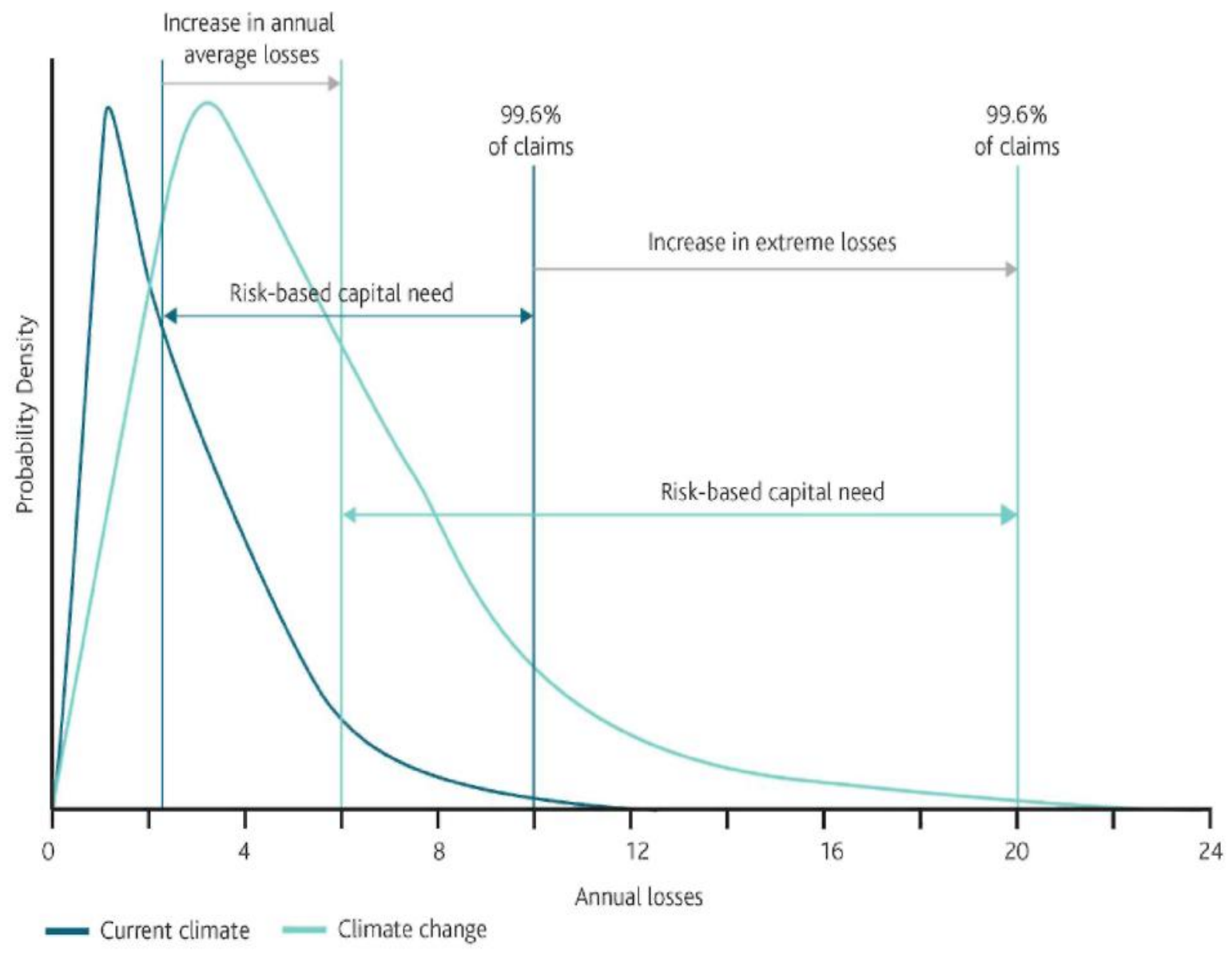

Source: ABI (2005), Financial risks of climate change, p.37 
In this field, the collaboration between public authorities and insurance industry is essential in order to implement a protection strategy by insurance against disasters ${ }^{1}$. But in some markets the insurance industry has developed new innovative forms of risk transfer thus allowing an increase in the financial capacity of the market. Alternatives to transferring the risk to reinsures or to the state, as insurer of last resort, include 'catastrophe bonds' (cat bonds) ${ }^{2}$. Cat bonds are securities that (re)insurance companies use to transfer natural catastrophe insurance risk to institutional investors in the form of bonds. As such, they help the (re)insurer to spread the peak exposures caused by extreme natural catastrophes by transferring the risk to the capital market.

Financial innovation permits greater competition among capital suppliers. In the last few years, clear and well-defined cat event risks have been brought directly to investors for the first time. This direct sourcing of investor capital can improve efficiency by removing layers of management, separating cat risk from equity risk, and improving the information with which those who bear the cat risk have to work.

Two basic methods of delivering cat-event risk directly to investors: financing transactions and risk-transfer transactions. Financing transactions are those that, upon the occurrence of an event, exchange funds from investors with securities. In a financing transaction, the securities require the insured to repay investors over time, and the exchange of securities for cash is done at fair value at the time of the exchange. Thus, when the cat event occurs, the investor loses no money: $\$ 100$ worth of securities is received in return for $\$ 100$ in cash. The main risk faced by investors, therefore, is that they are obliged to come up with the cash quickly. A standard credit facility with a bank is an example of a pure financing transaction (however, drawdown on a credit facility is generally not tied to cat events).

Risk transfer transactions are different. Here the investor loses when the cat event occurs. Specifically, the investor purchases securities with pre-determined event-linked payments. This exchange occurs before the cat event. If and when a cat event occurs, investors receive less-thanfull repayment. In this way, investors share in the event-linked loss of the insured. If no event occurs, investors share the insured's upside. With risk transfer, the insured company and its stockholders bear less cat event risk than they otherwise would. Reinsurance and insurance are examples of more or less risk-transfer arrangements, though they are not capital market instruments and they sometimes contain financing elements.

Risk transfers Solutions are likely to be a richer area for innovation than risk financing transactions. Better risk sharing - which is critical - can be accomplished only through better risk transfer. On the other hand, contingent risk financing can be accomplished in a number of ways. For example, the ability to perform straight financing operations (through debt, equity, or any other instrument) whenever desired obviates any strong need for contingent financing. Moreover, financing methods for general-purpose contingencies -such as bank credit facilities - are close substitutes and are widely available.

As the negative effects of climate change become increasingly apparent, the demand for insurance solutions to cover the costs resulting from weather-related catastrophes will grow. While this could offer a potential business opportunity, the requirements for insurability have to be met if coverage is to be realized.

The increasing demand goes hand-in-hand with an increasing risk exposure. The potential losses of certain weather-related catastrophes in regions with a high risk exposure might be too high for the insurance industry to bear on its own. The problems of adverse selection - the tendency of policyholders with high prospects of loss to buy more insurance products than buyers with lower prospect of loss - makes adequate diversification of the risks for insurers difficult, and need to be tackled.

\footnotetext{
${ }^{1}$ D. C. Dănulețiu, Asigurări comerciale, ed. Risoprint, Cluj-Napoca, 2007, p. 214.

${ }^{2}$ ABI, Financial risks of climate change, 2005, p.12
} 
The insurance industry is an innovative sector. Therefore, if public authorities, at all levels, work closely with insurers and reinsures, sustainable financial solutions can be found to provide insurance coverage for weather-related catastrophe risks which would otherwise be commercially unviable. As an example of territorial needs, one may for instance consider the specific developments of flood management authorities, to offer contractual indemnification to upstream landowners of dedicated over-flooding areas, in order to reduce the exposure of downstream main urban settlements.

In most countries, insurance coverage against extreme weather events is sold in combined manner with coverage against telluric perils (reflecting their natural risk profile), thus increasing mutualisation conditions.

\section{Conclusions}

Climate change is a global challenge. Addressing it will require an inclusive and coordinated approach across a wide range of policy areas. All members of society need to take responsibility as complacency is limiting the necessary risk reduction measures.

Insurers have expertise in the identification and analysis of risk, developing sustainable financial solutions and encouraging risk reducing behavior by both individuals and businesses. The Re/ Insurance industry wishes to play a full and proactive part in the climate change debate since it shares a common purpose with Politicians and other stakeholders to limit the economic consequences of climate change.

Private and voluntary insurance solutions have a number of advantages for society in comparison to state solutions when dealing with the consequences of climate change. Where possible the most efficient solutions must be sought, as the cost of climate change will continue to increase:

$\varnothing$ Insurance solutions promote adaptation, mitigation and prevention measures by providing incentives to reduce their exposure to the potential risks of climate change. In this way insurance is a catalyst driving responsible behavior individuals and businesses.

$\varnothing$ Insurance solutions reduce the burden on the public purse at a time European public finances are already under pressure due to other developments, such as the aging of the population.

$\varnothing$ Following a natural catastrophe it is important that those affected receive compensation as quickly as possible. As insurance solutions are funded before the event, insurers are in the position to process claims more quickly after the event than state donations which were not foreseen.

\section{Bibliography:}

1. Couilbault, Francois; Eliashberg, Constant - Les grandes principes de l'assurance, Paris, L'Argus, 2003

2. Dănulețiu, Dan-Constantin - Asigurări comerciale, Editura Risoprint, Cluj-Napoca, 2007

3. Seulean, Victoria; Barna Flavia, Chis Codruta - Asigurări comerciale, Editura Mirton, Timişoara, 2007

4. ABI (2005), Financial risks of climate change 